\title{
Wetting Characterization of Hybrid Coatings Deposited on Carbon Steel Collectors for Hydrophilic Modification
}

\author{
Chunyan Xu1, Jingcai Chang1,2, Jiaqiu Song², Xiang Wang1, Bo Zhang², Lin Cui1, \\ Chunyuan $\mathrm{Ma}^{1 *}$ \\ ${ }^{1}$ National Engineering Laboratory for Coal-fired Pollutants Emission Reduction, Shandong University, Jinan, \\ China \\ ${ }^{2}$ Shandong Shenhua Shanda Energy \& Environment Co., Ltd., Jinan, China \\ Email: "sdetechym@163.com
}

Received 25 October 2015; accepted 12 December 2015; published 15 December 2015

Copyright (C 2015 by authors and Scientific Research Publishing Inc.

This work is licensed under the Creative Commons Attribution International License (CC BY).

http://creativecommons.org/licenses/by/4.0/

(c) (;) Open Access

\section{Abstract}

The additional anticorrosive coating and hydrophilic layer of glass fiber cloth (GFC) deposited on the carbon steel sheet (CSS) was experimented and the surface wetting characteristic of the hydrophilic modified collection electrode was investigated under single strand feed water condition. The distilled water was selected as the working fluid. The influence of Reynolds number on the surface wetting characteristic parameters and those parameters at different temperatures were specifically studied. The results indicate that the GFC surface with loose glass fiber bundles reveals remarkable surface wetting characterizations. The saturated liquid holdup of this surface is 8 - 10 times more than that of the CSS surface; the surface flowrate value is 6 - 8 percent of that of the CSS surface; the film rate of this surface is 28 - 32 times more than that of the CSS surface; the average film thickness is between a third and a half of the value of the CSS surface. Good agreement is achieved between the WESPs working temperature and the experimental temperature range with remarkable wetting characterizations that provides a theoretical basis for the industrial application. Not satisfactorily, the hydrophilic modification surface is not able to survive high temperature.

\section{Keywords}

WESPs, Corrosion, Water Film, Wetting Characteristic, Flushing Liquid Distribution

\footnotetext{
${ }^{*}$ Corresponding author.
} 


\section{Introduction}

Wet electrostatic precipitators (WESPs) are well suited for collection of acid aerosols, ammonium salt aerosol and fine particulates [1] [2], as well as various contaminants such as mercury [3]-[5] and usually installed behind the wet flue gas desulfurization (WFGD) serving as terminal control equipment to purify the flue deeply. As a result, WESPs are drawing more and more attention from coal-fired power plants and dust emission factories. Usually, the temperature of the flue through the wet limestone-gypsum FGD is cooled down to $50^{\circ} \mathrm{C}-60^{\circ} \mathrm{C}$ [6] [7] and the discharging flue gas temperature of the ammonia process of desulfurization is about $70^{\circ} \mathrm{C}$ [8] [9]. At present, the WESPs are installed behind the wet flue gas desulfurization and the flue gas temperature in the WESPs is slightly lower than that of desulfurization tower outlet and even more lower to $46^{\circ} \mathrm{C}$ [2].

In most WESPs, the collection electrode with a function of supporting the water film [10] normally has the form of plain, rigid, continuous sheet of 316L stainless steel, duplex steel and glass fiber reinforced plastic [11]. Although with significant corrosion resistance, these substrates call for high investment cost and can't distribute the flushing liquid over the surface which results in the field voltage terminated, channeling, formation of dry spots and localized corrosion during flushing process [12] [13]. Therefore, the research of reasonable collection electrode modification methods which can increase the surface energy and form complete liquid film with ultralow water consumption so as to solve the traditional rigid plate needing high flushing water consumption, high cost and complex flushing water system process and so on has become the hot topic in the industry. As a result, flexible hydrophobic and insulated collection electrode of polypropylene [5] [14], terylene [15], silica fiber membranes [16] and carbon-fiber membranes [17] have been developed and tested.

But at present the research of vertical plate falling film flow characteristics focused on structured packing, heat transfer, nuclear power cooling shells [18]-[22] direction, their research contents focused on the film state on the vertical plate surface [23], the film fluctuation characteristics, etc., involved parameters include the disturbance frequency at the entrance, Reynolds number and the plate inclination angle, etc. [24]-[27]. The researches on the wetting characteristics and properties of collection electrode surface draw little attention.

In this paper, hydrophilic modification for the substrate of carbon steel collector sheet combining material corrosion resistance requirements is studied. The surface wetting characteristic of the hydrophilic modified collection electrode was investigated under single strand feed water condition. The distilled water was selected as the working fluid. The influence of Reynolds number on the surface wetting characteristic parameters and those parameters at different temperatures were specifically studied. This study aimed to provide theoretical foundation of the rinse water distribution on surface of the collection electrode in the WESPs.

\section{Experimental Apparatus and Method}

\subsection{Experimental Apparatus and Materials}

The experimental apparatus and layout are presented in Figure 1. The system is composed of water supply part, test part and data acquisition part. The first part includes a base support, a storage tank, a circulation pump, a triple valve, a water feed tank, a overflow tube and a needle valve; the in-between part includes a test sample, a sample holder, a collection tank, a feed holder and an electronic balance and the last part includes a camera and a computer with special software gathering weight signals connected to the electronic balance.

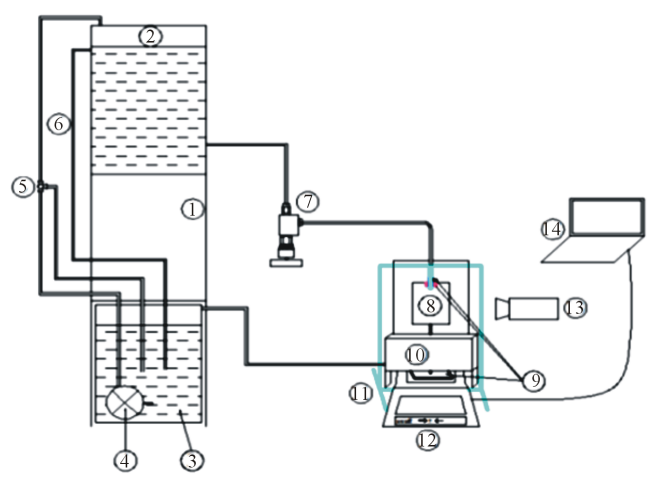

$$
\begin{aligned}
& \text { (1) Base support } \\
& \text { (2) Feed tank } \\
& \text { (3) Storage tank } \\
& \text { (4) Circulation pump } \\
& \text { (5) Tripe valve } \\
& \text { (6) Overflow tube } \\
& \text { (7) Needle valve } \\
& \text { (8) Test sample } \\
& \text { (9) Sample holder } \\
& \text { (1) Collection tank } \\
& \text { (11) Feed holder } \\
& \text { (12) Electronic balance } \\
& \text { (13) Camera } \\
& \text { (14) Computer }
\end{aligned}
$$

Figure 1. Schematic diagram of the experimental set-up. 
The working fluid employed was the distilled water. It passes through the water supply part before entering a liquid distributor fixed on the feed holder which could move with the feed holder motion. The distilled water falls down along the test sample surface due to gravitation and distributes horizontally due to capillary action assisted by gravitation and then drips down to the collection tank. After that the distilled water was send to the storage tank to use circularly. The circulation pump, the triple valve and the overflow tube cooperated to maintain a steady height level of the water feed tank. The flow rate of the distilled water was readily controlled through the head needle valve. The test sample was hanged over the sample holder and the holder was placed on the pan of the electronic balance. The camera fixed on the tripod was stand face to face with the test sample to take pictures of the stream flowing along the sample surface.

The test was run in the following procedure at the atmospheric environment. The water supply part worked firstly and the flow rate was adjusted to a certain value by the needle valve and the triple valve until the system was steady. Next, the test sample and the sample holder was placed on the pan of the electronic balance. Then move the feed holder to make sure that the liquid distributor was very closer to the test sample but without direct contact and the stream flowed down just along the sample surface. At the same time the camera and the computer took into actions respectively.

The test sample sheet is composed of a substrate of carbon steel sheet (Q215A), an anticorrosive coating and a glass fiber cloth layer. The substrate is $100 \times 80 \mathrm{~mm}^{2}$ with a thickness of $1.5 \mathrm{~mm}$. The substrate was polished with emery wheel and ultrasonically cleaned in alcohol and then was dried in warm air. All the treatments are carried out under the room temperature. The anticorrosive coating epoxy resin is a vinyl phenolic V-470. The accelerant and curing agent respectively was cobalt iso-octoate and methyl ethyl ketone peroxide (MEKP). All compounds were purchased from Yi Sheng Resin Co. Firstly 1\% - 2\% accelerant was incorporated in the epoxy resin and stirred well for few minutes, then $2 \%-4 \%$ curing agent was incorporated in the former mixed liquid and stirred thoroughly until completely combined. The liquid paints were applied by paint brush and after drying (ambient temperature for $24 \mathrm{~h}$ ), $100 \mathrm{ml}$ liquid paints could paint $1 \mathrm{~m}^{2}$ the treated substrate. The second layer coating followed the dried first layer coating. The third was same treated to the second and after few hours the glass fiber cloth was tiled onto the third uncured sticky paints surfaces. Exposed at ambient temperature for 168 $\mathrm{h}$ the test sample was obtained. The glass fiber cloth had an area density $220 \mathrm{~g} \cdot \mathrm{cm}^{-2}$ with a thickness of $0.25 \mathrm{~mm}$ and single fiber diameter of $9-13 \mu \mathrm{m}$. The details are shown in the Table 1.

The apparatus parameters are shown as following:

Electric drum wind drying oven (constant) FXB101-1, temperature control range: room temperature $+10^{\circ} \mathrm{C}$ $250^{\circ} \mathrm{C}$, the temperature fluctuation: $\pm 1^{\circ} \mathrm{C}$.

Precision electronic balance Mettler Toldeo XS204, weighing range: 0.0001 - 220.000 g, linearity error 0.2 $\mathrm{mg}$.

\subsection{Surface Wetting Characterizations Parameters Definition}

The film interface dynamics depends largely on the wettability of the test section surface and the surface tension of the working fluid [25]. Here, the working fluid employed was the distilled water as a result the film interface dynamics depends mainly on the former reason. The parameters describing surface wetting characterizations were listed below:

\subsubsection{Contact Angle}

In recent years, the surface exhibiting a water contact angle $\theta<65^{\circ}$ could be defined as hydrophilic surfaces [28]. The roughness or impurities on the solid surface could play an important role on the dynamic wetting be

Table 1. The description of modification methods on substrate surfaces.

\begin{tabular}{ccccc}
\hline Methods & 1 & 2 & 3 & 4 \\
\hline Name & Carbon steel sheet (substrate) & Epoxy resin & ER + glass fiber cloth & ER + 4 hours interval + GFC \\
Features & Q215A & V-470 & $\delta=0.25 \mathrm{~mm}$ \\
$220 \mathrm{~g} \cdot \mathrm{cm}^{-2}$ & $\delta=0.25 \mathrm{~mm}$ \\
Code & CSS & ER & GFCI & GFCII \\
\hline
\end{tabular}


havior [29]. As a result, contact angle can represent the wetting capacity of liquid toward solid surface. The static contact angle is measured with the Kruss-K12 Program Interface Tensiometer.

\subsubsection{Liquid Holdup}

Liquid holdup $\left(m_{h}\right)$ is defined as the liquid quantity staying on per unit solid surface area during the flowing progress. Saturated liquid holdup $\left(m_{s h}\right)$ refers to the largest liquid hold quantity.

$$
m_{h}=\frac{G_{h}}{a_{t}}
$$

$G_{h}$ is the liquid quantity staying on the test sample sheet, $a_{t}$ is the test sample sheet total area.

\subsubsection{Surface Flowrate}

Surface flowrate $\left(q_{h}\right)$ is defined as the supply water flow rate which can keep continuous film flowing per unit solid surface area.

$$
q_{h}=\frac{Q_{t}}{a_{e}} \times 36,000
$$

$Q_{t}$ is the supply water flow rate, $a_{e}$ is the effective film area.

\subsubsection{Film Rate}

The distilled water falls down along the test sample sheet surface due to gravitation and distributes horizontally due to capillary action. Scaleplate was stick to the test sample sheet three edges (up, right and left). The water film images were took pictures by a single-lens reflex camera and then the pictures are treated with Adobe Photoshop to calculate the effective water film area [30]. Film rate is defined as the ratio of the effective water film area to the total test sample surface area.

$$
\eta=\frac{a_{e}}{a_{t}} \times 100 \%
$$

\subsubsection{Average Film Thickness}

Average film thickness is defined as the thickness of liquid holdup on per unit effective water film area.

$$
\bar{\delta}=\frac{G_{h}}{\rho a_{e}}
$$

\subsubsection{Critical Saturation Time}

For the test sample sheet surface film rate being $100 \%$, the quantity of the liquid holdup begins to slowly increase to saturated quantity with the passage of time after the amount of the liquid holdup reached 95 percents of the saturation value. At the moment, the effective film area on the surface no longer changes and the liquid holdup can keep the entire surface wetting. So the time that liquid holdup reached 95 percents saturation liquid holdup is defined as critical saturation time.

\subsubsection{Temperature Influence}

The wetting characteristic parameters of GFC surface at different temperatures affect the performance of the WESPs, according to the WESPs working temperature, a test temperature range $40^{\circ} \mathrm{C}-90^{\circ} \mathrm{C}$ is chose. All test sample sheets are put in the electric drum wind drying oven which starts heating from $40^{\circ} \mathrm{C}$ and maintains the temperature for 48 hours. Then take one of them out and let it cool down at the atmospheric environment. Then, the oven rises $10^{\circ} \mathrm{C}$ once with repeating the former operations.

\section{Experimental Results and Discussion}

\subsection{Surface Appearance}

As shown in Figure 2, the carbon steel sheet surface (a) emerges gill structure after polished, the substrate with three epoxy resin anticorrosive coatings (b) has a smooth surface, the glass fiber cloth was woven crosswise, the 


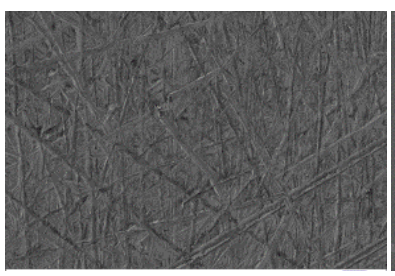

(a)

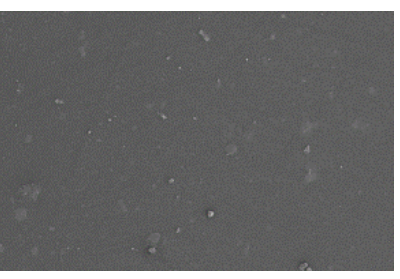

(b)

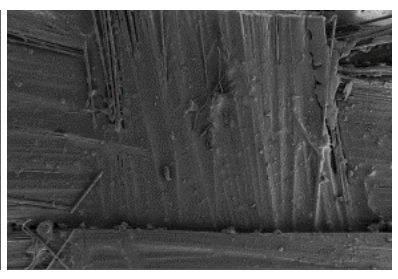

(c)

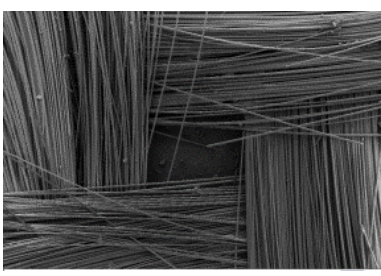

(d)

Figure 2. SEM images of surfaces: (a) CSS, (b) ER, (c) GFCI, (d) GFCII.

loose glass fiber bundles are soaked with epoxy resin on the surface that the substrate with three epoxy resin anticorrosive coatings and after zero hours the glass fiber cloth is tiled onto the former surface(c) while the up layer glass fiber bundles stay loose and unbounded, the anticorrosive coating surface is apparent under the glass fiber bundles on the surface that the substrate with three epoxy resin anticorrosive coatings and after four hours the glass fiber cloth is tiled onto the former surface(d).

\subsection{Surface Wetting Characterizations}

Per $5.0 \mu \mathrm{L}$ distilled water is taken as the probe liquid and the static contact angle is measured at least in 5 different positions on the test sample surface of which the average value is taken as the final result. The contact angle of various surfaces are shown in Table 2, the contact angle of substrate carbon steel sheet surface is $56^{\circ}$, the surface of substrate with three epoxy resin anticorrosive coatings exhibits a water contact angle $61^{\circ}$, the contact angle of GFCI surface decreases $6^{\circ}$ compared to the ER surface and almost is same with the CSS surface. On the contrary, the water droplet spreads out rapidly once it falls on the GFCII surface which exhibits a water contact angle $0^{\circ}$.

Figure 3(a) shows the influence of Reynolds number on saturated liquid holdup for four surfaces. The saturated liquid holdup of CSS, ER and GFCI surfaces increase with Reynolds number. The GFCII surface has a higher value, irrespectively of Reynolds number in comparison to the former surfaces. The CSS surface has a saturated liquid holdup range of $0.001-0.002 \mathrm{~g} / \mathrm{cm}^{2}$ while the maximum value of $0.002 \mathrm{~g} / \mathrm{cm}^{2}$ is only 12 percent of the GFCII surface value of $0.017 \mathrm{~g} / \mathrm{cm}^{2}$. With the epoxy resin anticorrosive coatings, the saturated liquid holdup reduces compared with the CSS surface. The GFCI surface decreases more than the ER surface at lower Reynolds number, but the value approaches at a higher Reynolds number $(\mathrm{R}>3500)$ even exceeds at a Reynolds number of 4000. Deceleration of the saturated liquid holdup growth appears after Reynolds number reached 2150 .

Figure 3(b) presents the influence of Reynolds number on surface flowrate for four surfaces. The surface flowrate for GFCII surface with a largest value $360 \mathrm{~kg} /\left(\mathrm{h} \cdot \mathrm{m}^{2}\right)$ is far less than that for the others among which the largest value exceeds $4950 \mathrm{~kg} /\left(\mathrm{h} \cdot \mathrm{m}^{2}\right)$. The surface flowrate is influenced by the effective water film area directly. The water film area is described by the film rate. The influence of Reynolds number on film rate is depicted in Figure 4(a). Water film occupies the GFCII surface totally that the film rate is 100 percent. As a result, the surface flowrate of GFCII surface has a linear dependence on the Reynolds number. The film rate of the CSS surface varies from 2.8 to 3.5 percent with Reynolds number, which varies from 2.5 to 3.0 percent for the ER surface and from 2.4 to 3.1 percent for the GFCI surface. The film rate of the ER surface is superior to the GFCI surface with Reynolds number $<3470$ and when Reynolds number $>3470$ the GFCI surface exceeds the ER surface. Maybe the morphology of GFCI surface makes a difference when Reynolds number $>3470$. And so these three surfaces have approximate linear relation for corresponding variation of the film rate.

The average film thickness can exhibit the distribution capacity of water on the surfaces. As shown in Figure 4(b), the average film thickness of the GFCII surface has a same value with its saturated liquid holdup because the film rate is 100 percent. The ER surface has a thickest film which no longer thickens when Reynolds number $>2150$. The average film thickness of the GFCI surface is thicker than the CSS surface and thinner than the ER surface.

Given the above, the GFCII surface reveals remarkable surface wetting characterizations. The saturated liquid holdup of this surface is 8 - 10 times more than that of the CSS surface, the surface flowrate value is 6 - 8 percent of that of the CSS surface, the film rate of this surface is 28 - 32 times more than that of the CSS surface, 
Table 2. Contact angle of surfaces.

\begin{tabular}{ccccc}
\hline Surfaces & CSS & ER & GFCI & GFCII \\
\hline $\mathrm{CA}{ }^{\circ}$ & 56 & 61 & 55 & 0 \\
\hline
\end{tabular}

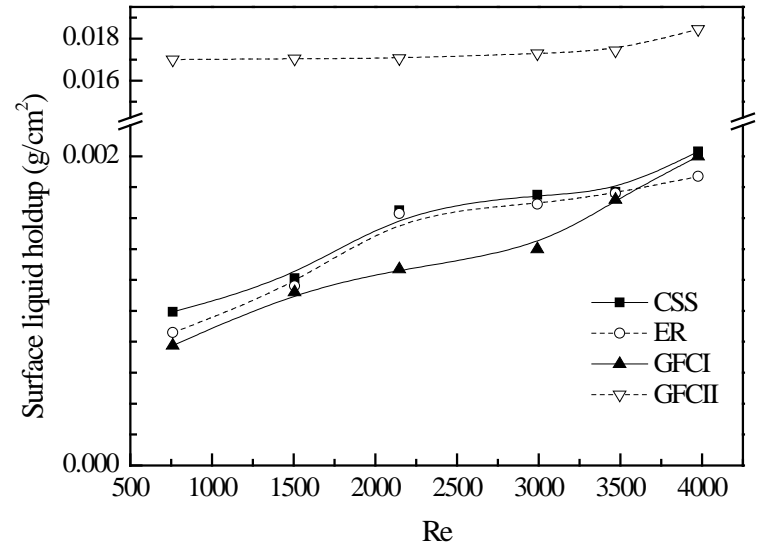

(a)

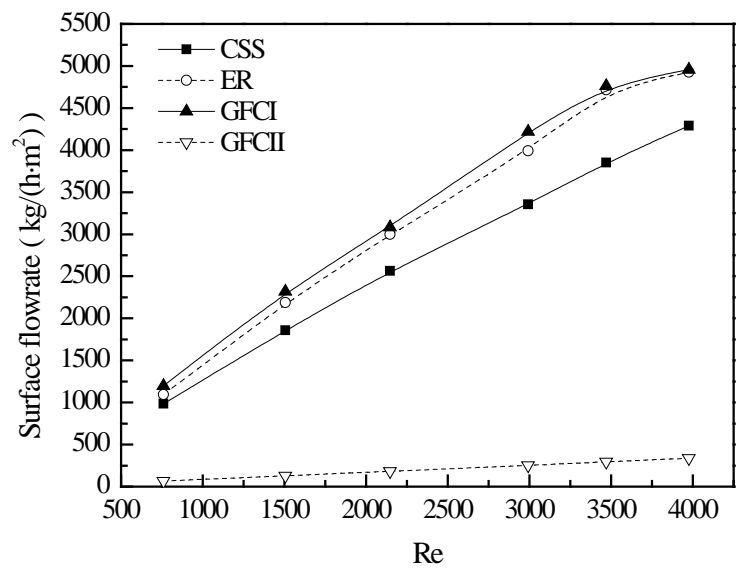

(b)

Figure 3. Influence of Reynolds number on saturated liquid holdup and surface flowrate. (a) Saturated liquid holdup; (b) Surface flowrate.

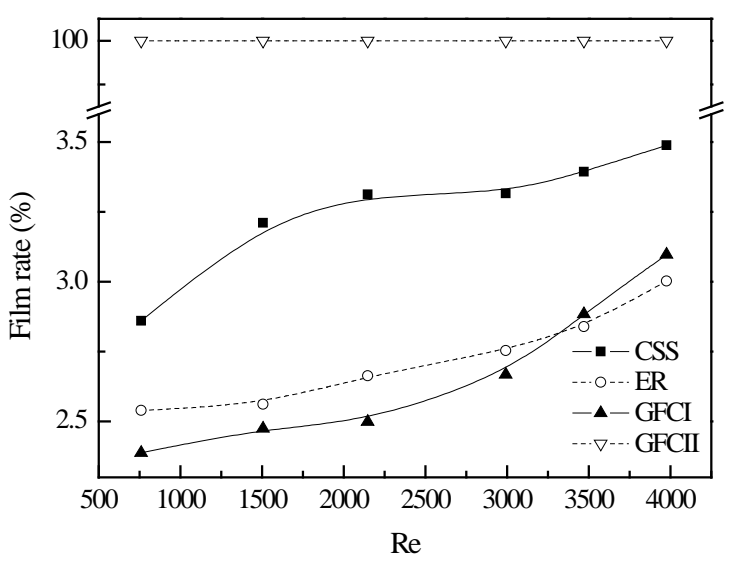

(a)

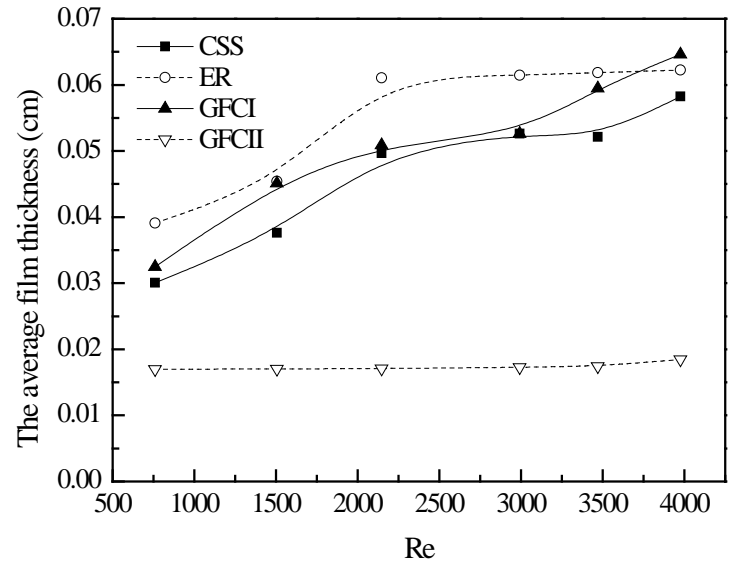

(b)

Figure 4. Influence of Reynolds number on film rate and average film thickness. (a) Film rate; (b) Average film thickness.

the average film thickness is between a third and a half of the value of the CSS surface. And when Reynolds number $>2150$ the surface wetting characterizations the saturated liquid holdup, the film rate and the average film thickness have no obvious increase with Reynolds number.

\subsection{Temperature Influence}

The temperature influence on the wetting characteristic parameters of GFCII surface at flow rate of $0.22 \mathrm{~g} / \mathrm{s}(\mathrm{Re}=$ 3100) are listed in Table 3. As shown in the table, the initial weight $\mathrm{w}_{\text {in }}$ refers to total weight of the holder and test sample placed on the electronic scales. When the film rate is $100 \%$, the average film thickness has a same value with the saturated liquid holdup and the relative error between the test and the fitted saturated liquid holdup is lower than $\pm 5 \%$. The consistent surface flowrate at different temperatures is due to the $100 \%$ effective water film area and the same feed water flow rate. Figure 5 showed the surface liquid holdup test data at 
Table 3. The temperature influence on the wetting characteristic parameters of GFCII surface at flow rate of $0.22 \mathrm{~g} / \mathrm{s}(\mathrm{Re}=$ 3100).

\begin{tabular}{|c|c|c|c|c|c|c|c|c|}
\hline $\begin{array}{l}\text { Sample } \\
\text { code }\end{array}$ & $\begin{array}{c}w_{\text {in }} \\
\mathrm{g}\end{array}$ & $\begin{array}{c}q_{h} \\
\mathrm{~kg} /\left(\mathrm{h} \cdot \mathrm{m}^{2}\right)\end{array}$ & $\begin{array}{l}\eta \\
\%\end{array}$ & $\begin{array}{c}\bar{\delta} \\
\mathrm{cm}\end{array}$ & $\begin{array}{l}\text { Test } m_{\text {sh }} \\
\mathrm{g} / \mathrm{cm}^{2}\end{array}$ & $\begin{array}{l}\text { Fitted } m_{\mathrm{sh}} \\
\mathrm{g} / \mathrm{cm}^{2}\end{array}$ & $\begin{array}{c}m_{s h} \text { relative error } \\
\%\end{array}$ & $\begin{array}{l}\boldsymbol{t}_{c} \\
\mathrm{~s}\end{array}$ \\
\hline $40^{\circ} \mathrm{C}$ & 131.38 & 97.24 & 100 & 0.01705 & 0.01705 & 0.01748 & 2.522 & 159 \\
\hline $50^{\circ} \mathrm{C}$ & 130.53 & 97.24 & 100 & 0.02030 & 0.02030 & 0.02049 & 0.936 & 55 \\
\hline $60^{\circ} \mathrm{C}$ & 128.95 & 97.24 & 100 & 0.01617 & 0.01617 & 0.01624 & 0.433 & 176 \\
\hline $70^{\circ} \mathrm{C}$ & 128.94 & 97.24 & 100 & 0.01751 & 0.01751 & 0.01783 & 1.828 & 279 \\
\hline $80^{\circ} \mathrm{C}$ & 130.94 & 97.24 & 100 & 0.01868 & 0.01868 & 0.01855 & -0.696 & 499 \\
\hline $90^{\circ} \mathrm{C}$ & 130.09 & 97.24 & 100 & 0.01101 & 0.01101 & 0.01124 & 2.089 & 3696 \\
\hline
\end{tabular}

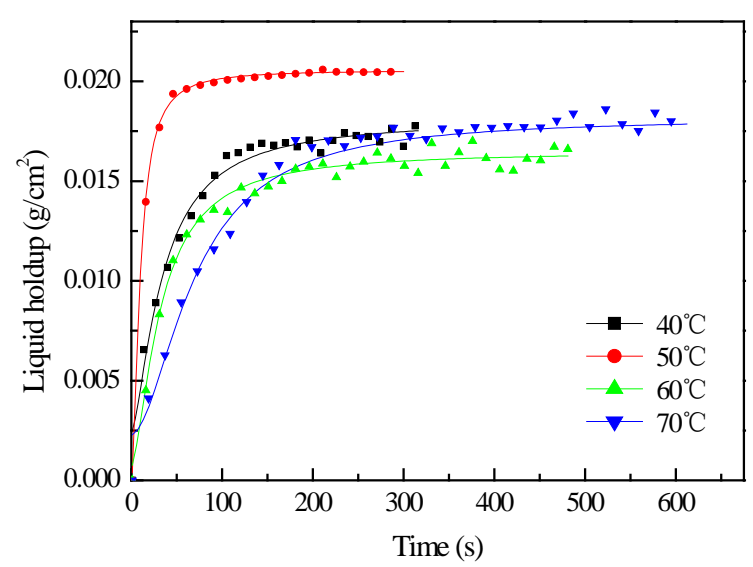

(a)

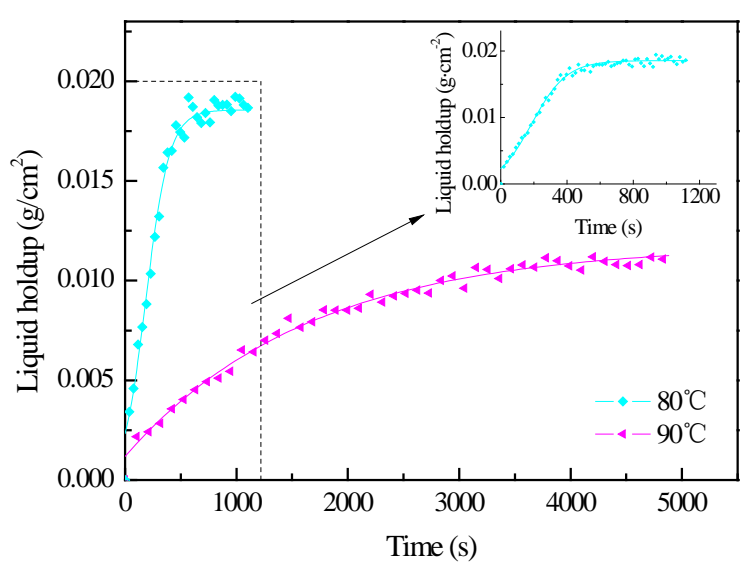

(b)

Figure 5. The surface liquid holdup at different temperatures changed by the time at flow rate of $0.22 \mathrm{~g} / \mathrm{s}(\mathrm{R}=3100)$. (a) $40^{\circ} \mathrm{C}-70^{\circ} \mathrm{C}$; (b) $80^{\circ} \mathrm{C}-90^{\circ} \mathrm{C}$.

different temperatures changing by the time at flow rate of $0.22 \mathrm{~g} / \mathrm{s}(\mathrm{Re}=3100)$ and the corresponding fitted curves of the samples. The critical saturation time is read out of the fitted curve through calculated with the data got and fitted.

The liquid holdup of surface with a temperature $50^{\circ} \mathrm{C}$ presents an approximately vertical raise once the distilled water contacting the surface, in the end the surface liquid holdup reaches steady and saturated with a certain value. The liquid holdup of surface with the temperature $40^{\circ} \mathrm{C} / 60^{\circ} \mathrm{C} / 70^{\circ} \mathrm{C} / 80^{\circ} \mathrm{C}$ rises slower than that of the temperature $50^{\circ} \mathrm{C}$ and reaches steady and saturated with a certain value in different numbers of seconds. With temperature $40^{\circ} \mathrm{C}-80^{\circ} \mathrm{C}$ the critical saturation time is less than 500 seconds which is suitable in the industrial application and the saturated liquid holdup is more than $0.0162 \mathrm{~g} / \mathrm{cm}^{2}$ which is 8 times more than that of the CSS surface. The liquid holdup of surface with a temperature $90^{\circ} \mathrm{C}$ rises very slowly with the critical saturation time exceeding 3600 seconds and the saturated liquid holdup is only $0.0110 \mathrm{~g} / \mathrm{cm}^{2}$. The surface liquid holdup at temperature $40^{\circ} \mathrm{C} / 50^{\circ} \mathrm{C} / 60^{\circ} \mathrm{C} / 70^{\circ} \mathrm{C}$ conforms to Hill 1 distribution respectively, $80^{\circ} \mathrm{C}$ conforms to DoseResp distribution and $90^{\circ} \mathrm{C}$ conforms to Exponential distribution. The fitted parameters of surface liquid holdup at different temperatures changing by the time at flow rate of $0.22 \mathrm{~g} / \mathrm{s}(\mathrm{Re}=3100)$ are shown in Table 4.

\section{Conclusions}

The wetting characterizations and properties of hybrid coatings deposited onto carbon steel collectors for hydrophilic modification have been researched.

The GFC surface with loose glass fiber bundles reveals remarkable wetting characterizations. When Reynolds number $>2150$, the surface wetting characterizations such as the saturated liquid holdup, the film rate and the 
Table 4. The fitted parameters of the surface liquid holdup at different temperatures changing by the time at flow rate of 0.22 $\mathrm{g} / \mathrm{s}(\mathrm{Re}=3100)$.

\begin{tabular}{|c|c|c|c|c|c|}
\hline Sample code & Fitted curve formula & Parameters & Value & Standard error & $\mathrm{R}^{2}$ \\
\hline \multirow{4}{*}{$40^{\circ} \mathrm{C}$} & & $A_{1}$ & 0.19154 & \pm 0.01866 & \multirow{4}{*}{0.98003} \\
\hline & & $A_{2}$ & 1.44864 & \pm 0.00826 & \\
\hline & & $k$ & 34.4238 & \pm 0.86763 & \\
\hline & & $n$ & 1.46785 & \pm 0.04925 & \\
\hline \multirow{5}{*}{$50^{\circ} \mathrm{C}$} & & $A_{1}$ & -0.00402 & \pm 0.02533 & \multirow{4}{*}{0.98276} \\
\hline & & $A_{2}$ & 1.64515 & \pm 0.00286 & \\
\hline & & $k$ & 9.9085 & \pm 0.25777 & \\
\hline & $G_{-A}\left(A_{2}-A_{1}\right) \times t^{n}$ & $n$ & 1.6715 & \pm 0.04058 & \\
\hline & $G_{t}=A_{1}+\frac{k^{n}+t^{n}}{n^{n}}$ & $A_{1}$ & 0.05437 & \pm 0.01667 & \multirow{4}{*}{0.97728} \\
\hline \multirow{3}{*}{$60^{\circ} \mathrm{C}$} & & $A_{2}$ & 1.32028 & \pm 0.00413 & \\
\hline & & $k$ & 32.19624 & \pm 0.7413 & \\
\hline & & $n$ & 1.53483 & \pm 0.03863 & \\
\hline \multirow{4}{*}{$70^{\circ} \mathrm{C}$} & & $A_{1}$ & 0.20323 & \pm 0.01113 & \multirow{4}{*}{0.98172} \\
\hline & & $A_{2}$ & 1.45267 & \pm 0.00443 & \\
\hline & & $k$ & 70.97169 & \pm 0.99478 & \\
\hline & & $n$ & 1.80698 & \pm 0.03879 & \\
\hline \multirow{4}{*}{$80^{\circ} \mathrm{C}$} & & $A_{1}$ & -0.02828 & \pm 0.01708 & \multirow{4}{*}{0.99015} \\
\hline & $\left(A_{2}-A_{1}\right)$ & $A_{2}$ & 1.48459 & \pm 0.00181 & \\
\hline & $G_{t}=A_{1}+\overline{1+10^{\left(t_{0}-t\right) \times p}}$ & $t_{0}$ & 186.9575 & \pm 2.91924 & \\
\hline & & $p$ & 0.00412 & $\pm 6.08 \mathrm{E}-05$ & \\
\hline \multirow{3}{*}{$90^{\circ} \mathrm{C}$} & & $G_{0}$ & 0.94473 & \pm 0.00132 & \multirow{3}{*}{0.98794} \\
\hline & $G_{t}=G_{0}+A e^{k t}$ & $A$ & -0.84952 & \pm 0.00136 & \\
\hline & & $k$ & $-6.06 \mathrm{E}-04$ & $\pm 3.01 \mathrm{E}-06$ & \\
\hline
\end{tabular}

average film thickness have no obvious increase with Reynolds number and the surface morphology has a great influence on the wetting characterizations.

The flue gas temperature in the WESPs is cooled down to $40^{\circ} \mathrm{C}-70^{\circ} \mathrm{C}$. The modified sample with treatment temperature $40^{\circ} \mathrm{C}-70^{\circ} \mathrm{C}$ has remarkable surface wetting properties. As a consequence, good agreement is achieved between the WESPs working temperature and the experimental temperature range. That can provide a theoretical basis for the industrial application. Not satisfactorily, the hydrophilic modification surface is not able to survive high temperature.

\section{Acknowledgements}

This work was financially supported by the National Natural Science Foundation of China (Grant No. 51206097 and 51006063), supported by Shandong Province Natural Science Foundation, China (Grant No. ZR2011 EEQ019) and the Fundamental Research Funds of Shandong University.

\section{References}

[1] Anderlohr, C., Brachert, L., Mertens, J. and Schaber, K. (2015) Collection and Generation of Sulfuric Acid Aerosols in 
a Wet Electrostatic Precipitator. Aerosol Science and Technology, 49, 144-151.

http://dx.doi.org/10.1080/02786826.2015.1008624

[2] Mertens, J., Anderlohr, C., Rogiers, P., et al. (2014) A Wet Electrostatic Precipitator (WESP) as Countermeasure to Mist Formation in Amine Based Carbon Capture. International Journal of Greenhouse Gas Control, 31, 175-181. http://dx.doi.org/10.1016/j.ijggc.2014.10.012

[3] Fujishima, H. and Tsuchiya, Y. (1993) Application of Wet Type Electrostatic Precipitators for Utilities' Coal-Fired Boiler. Joint Conference of 10th Particle Control Symposium and 5th International Conference on Electrostatic Precipitation, Washington DC, 5-8 April 1993.

[4] Ueda, Y., Tomimatsu, K., Kagami, M. and Fujishima, H. (2001) Development of Advanced Gas Cleaning System for Sub-Micron Particle Removal. 8th International Conference on Electrostatic Precipitation, Birmingham, May 2001.

[5] Bayless, D.J., Shi, L.M., Kremer, G., Stuart, B.J., Reynolds, J. and Caine, J. (2005) Membrane-Based Wet Electrostatic Precipitation. Journal of the Air \& Waste Management Association, 55, 784-791. http://dx.doi.org/10.1080/10473289.2005.10464658

[6] Zheng, Y.J. and Hu, Y.F. (2009) The Analysis and Research of the Performance Factors in the Wet Electrostatic Precipitators. Science \& Technology Information, 24, 234.

[7] Córdoba, P., Ayora, C., Moreno, N., et al. (2013) Influence of an Aluminium Additive in Aqueous and Solid Speciation of Elements in Flue Gas Desulphurisation (FGD) System. Energy, 50, 438-444. http://dx.doi.org/10.1016/j.energy.2012.11.020

[8] Shen, L.Y. (2006) The Computation of Material Balance for an Advanced Ammonia Desulphurization Technology and the Performance Optimization of the Mist Separator. North China Electric Power University, Beijing.

[9] Zhang, A.P. (2009) The Application of Coal-Fired Boiler Flue Gas Ammonia Desulphurization Technology. Environmental Science Survey, 28, 58-61.

[10] Gao, J.G., Huang, C. and Qi, X.D. (2007) Membrane Electrostatic Precipitator-A New Technique of Electrostatic Precipitation. Jiangsu Environmental Science and Technology, 20, 64-67.

[11] Jiang, H.T., Tian, S.G., Fu, Y.L., Jia, M.H. and Zhang, Y.B. (2014) Application of Wet Electrostatic Precipitator in Coal-Fired Power Plants. Power Equipment, 28, 61-64.

[12] Xue, M.J. and Zong, N.S. (1997) Characteristics of the Wet Electrostatic Precipitator and a Direction of Development. Electric Power Environmental Protection, 13, 40-44.

[13] Bayless, D.J., Shi, L.M., Kremer, G., Stuart, B.J., Reynolds, J. and Caine, J. (2005) Membrane-Based Wet Electrostatic Precipitation. Journal of the Air \& Waste Management Association, 55, 784-791. http://dx.doi.org/10.1080/10473289.2005.10464658

[14] Chang, J.C., Dong, Y., Yan, J., Li, B. and Ma, C.Y. (2010) Performance Test of a New Wet ESP with Flexible Collection Electrodes. Proceedings of the 4th International Conference on Bioinformatics and Biomedical Engineering, Chengdu, 18-20 June 2010, 1-4.

[15] Chang, J.C., Dong, Y., Wang, Z.Q., Wang, P., Chen, P. and Ma, C.Y. (2011) Removal of Sulfuric Acid Aerosol in Wet Electrostatic Precipitator with Single Terylene or Polypropylene Collection Electrode. Journal of Aerosol Science, 42, 544-554. http://dx.doi.org/10.1016/j.jaerosci.2011.05.006

[16] Bayless, D.J., Alam, M.K., Radcliff, R., et al. (2004) Membrane-Based Wet Electrostatic Precipitation. Fuel Processing Technology, 85, 781-798. http://dx.doi.org/10.1016/j.fuproc.2003.11.025

[17] Bayless, D.J., Pasic, H., Alam, M.K., et al. (2001) Use of Membrane Collectors in Electrostatic Precipitators. Journal of the Air \& Waste Management Association, 51, 1401-1407. http://dx.doi.org/10.1080/10473289.2001.10464372

[18] Miyara, A. (2000) Numerical Simulation of Wavy Liquid Film Flowing Down on Vertical Wall and an Inclined Wall. International Journal of Thermal Sciences, 39, 1015-1027. http://dx.doi.org/10.1016/S1290-0729(00)01192-3

[19] Zhao, X.G., Li, W., Zhang, Z.B. and Xu, Y.H. (2011) Suppression of Liquid Film Rupture during Falling Film Evaporation for High Salinity Wastewater. Chinese Journal of Environmental Engineering, 5, 726-730.

[20] La, D. (2007) The Perpendicular Wall That Takes Patulous Side Falls Film Evaporates Mechanism Research. Master’s Thesis, Tongji University, Shanghai.

[21] Luo, D.Q., Li, Y.C., Fang, Y. and Dai, G. (2011) Wettability of Modified Polymer Surface and Liquid Film Behavior. Journal of East China University of Science and Technology (Natural Science Edition), 37, 274-280.

[22] Lu, C., Duan, R.Q. and Jiang, S.Y. (2008) Experimental Study of Flow Instabilities of Falling Films. Journal of Tsinghua University (Sci \& Tech), 48, 1487-1489.

[23] De Castro, M.S. and Rodriguez, O.M.H. (2015) Interfacial Waves in Stratified Viscous Oil-Water Flow. Experimental Thermal and Fluid Science, 62, 85-98. http://dx.doi.org/10.1016/j.expthermflusci.2014.12.003

[24] Zhao, L. and Cerro, R.L. (1992) Experimental Characterization of Viscous Film Flows over Complex Surfaces. Inter- 
national Journal of Multiphase Flow, 18, 495-516. http://dx.doi.org/10.1016/0301-9322(92)90048-L

[25] Zhou, D.W., Gambaryan-Roisman, T. and Stephan, P. (2009) Measurement of Water Falling Film Thickness to Flat Plate Using Confocal Chromatic Sensoring Technique. Experimental Thermal and Fluid Science, 33, 273-283. http://dx.doi.org/10.1016/j.expthermflusci.2008.09.003

[26] Takamasa, T. and Hazuku, T. (2000) Measuring Interfacial Waves on Film Flowing down a Vertical Plate Wall in the Entry Region Using Laser Focus Displacement Meters. International Journal of Heat and Mass Transfer, 43, 28072819. http://dx.doi.org/10.1016/S0017-9310(99)00335-X

[27] Moran, K., Inumaru, J. and Kawaji, M. (2002) Instantaneous Hydrodynamics of a Laminar Wavy Liquid Film. International Journal of Multiphase Flow, 28, 731-755. http://dx.doi.org/10.1016/S0301-9322(02)00006-X

[28] Vogler, E.A. (1998) Structure and Reactivity of Water at Biomaterial Surfaces. Advances in Colloid and Interface Science, 74, 69-117. http://dx.doi.org/10.1016/S0001-8686(97)00040-7

[29] Katoh, K., Wakimoto, T., Yamamoto, Y., et al. (2015) Dynamic Wetting Behavior of a Triple-Phase Contact Line in Several Experimental Systems. Experimental Thermal and Fluid Science, 60, 354-360. http://dx.doi.org/10.1016/j.expthermflusci.2014.05.006

[30] Li, B.G., Tao, X.H. and Ni, G.P. (2006) Study on Determining Plant Leaf Area by Scanning Image Pixels Method. Acta Agricultural Jiangxi, 18, 78-81.

\section{Nomenclature}

$m_{h} \quad$ liquid holdup $\left(\mathrm{g} / \mathrm{cm}^{2}\right)$

$a_{e} \quad$ effective film area (cm)

$m_{s h} \quad$ saturated liquid holdup $\left(\mathrm{g} / \mathrm{cm}^{2}\right)$

$t_{c} \quad$ critical saturation time (s)

$G_{h} \quad$ liquid quantity (g)

$\eta \quad$ film rate (\%)

$a_{t} \quad$ sample sheet total area $\left(\mathrm{cm}^{2}\right)$

$\delta \quad$ average film thickness $(\mathrm{cm})$

$q_{h} \quad$ surface flowrate $\left(\mathrm{kg} /\left(\mathrm{h} \cdot \mathrm{m}^{2}\right)\right)$

$\rho \quad$ water density $\left(\mathrm{g} / \mathrm{cm}^{3}\right)$

$Q_{t} \quad$ supply water flow rate (g/s)

Re Reynolds number in liquid distribution tube (dimensionless) 